\title{
Influência da densidade de cultivo de dois genótipos de milho na severidade da mancha de cercospora e no rendimento de grãos na 'safrinha'
}

\section{Effect of crop density of two genotypes of maize in the severity of gray leaf spot and yield in the second season crop}

\author{
Rafael Rodrigues da Silva ${ }^{1}$; Gustavo de Faria Theodoro ${ }^{2 *}$; \\ Cláudia Barrios de Libório'; Luis Gustavo Amorim Pessoa ${ }^{2}$
}

\section{Resumo}

Entre as doenças que incidem na cultura do milho e podem reduzir seu rendimento, há a mancha de cercospora, causada por Cercospora spp., especialmente importante em milho de segunda época, ou 'safrinha'. O objetivo deste trabalho foi avaliar a severidade da cercosporiose em nos híbridos transgênicos de milho Agroceres Yieldgard AG 9010 YG e Advance NK Agrisure TL (Bt11), em duas densidades de cultivo: 78.000 e 100.000 plantas por hectare. Os resultados permitiram constatar que a menor densidade de plantas favoreceu o incremento da severidade da doença e proporcionou menor rendimento de grãos. Não houve interação significativa entre os híbridos e a severidade da doença.

Palavras-chave: Zea mays, doença, controle integrado, produtividade, Cercospora zeae-maydis, Cercospora zeina, Cercospora sorghi var. maydis

\begin{abstract}
Among the diseases that affect the corn crop and can reduce the yield, there is cercospora gray leaf, caused by Cercospora spp. This disease is very important in the second season crop or 'safrinha'. The objective of this study was to evaluate the severity of cercospora leaf spot in transgenic corn hybrids Agroceres Yieldgard AG 9010 YG and Advance NK Agrisure TL (Bt11), using two plant densities: 78,000 and 100,000 plants per hectare. The results showed that the higher density of plants increased the severity of the disease and provided a lower yield. There was no significant interaction between hybrids and severity of the disease.

Key words: Zea mays, disease, integrated control, Cercospora zeae-maydis, Cercospora zeina, Cercospora sorghi var. maydis
\end{abstract}

\footnotetext{
${ }^{1}$ Discente(s) do Curso de Agronomia da Universidade Federal de Mato Grosso do Sul, UFMS, Campus de Chapadão do Sul, Chapadão do Sul. E-mail: rafael silwa@hotmail.com; liborio@hotmail.com

${ }^{2}$ Engenheiros Agrônomos, Profs. Drs. Adjunto da UFMS, Campus de Chapadão do Sul. E-mail: gustavo.theodoro@ufms.br; luis. pessoa@ufms.br

*Autor para correspondência
} 
Atualmente, o milho (Zea mays L.) destaca-se como um dos cereais mais cultivados no mundo, superado apenas pelo trigo e arroz (TRENTO; IRGANG; REIS, 2002). Em 1980, iniciou-se uma impactante mudança no mercado de milho no Brasil, pois grãos foram ofertados em uma segunda época, pelo cultivo no Paraná de uma segunda safra, a qual sucedeu a safra oficial de verão. Posteriormente, essa safra, também conhecida como 'safrinha', foi popularizada entre os produtores de grãos de outros Estados da federação.

A cultura do milho no Brasil esta sujeita à ocorrência de várias doenças, que podem comprometer o seu rendimento. Dentre elas, estão aquelas relacionadas às manchas foliares causadas, em sua grande maioria, por fungos (CASA et al., 2007).

A mancha de cercospora pode ser causada por Cercospora zeae-maydis, Cercospora zeina e Cercospora sorghi var. maydis (CROUS et al., 2006). É uma doença de grande importância para a cultura do milho, pois é considerada como uma das que mais limitam a produtividade dessa cultura no Brasil (PEREIRA; CARVALHO; CAMARGO, 2005). Conforme Casela e Ferreira (2003), a severidade da mancha de cercospora aumenta em condições de alta umidade relativa (90\%) e temperatura diurna variando de moderada a alta (22 a $32{ }^{\circ} \mathrm{C}$ ) bem como com noites frias, com formação de orvalho.

O impacto dessa doença na cultura se deve ao fato de o patógeno colonizar grande parte do tecido foliar, diminuindo a área fotossintetizante, levando à senescência precoce e, consequentemente, à redução da produtividade (BRITO et al., 2007). No Estado de São Paulo, durante as safrinhas de 2004 a 2008, Fantin et. al. (2008) avaliaram a influência da severidade da mancha de cercospora sobre a produtividade do milho, em mais de 44 híbridos simples e triplos. Foi notado que, mesmo a partir de baixas severidades da doença, observaram-se reduções na produtividade do milho. Conforme relatado por vários autores (WARD; LAING; NOWELL, 1997b; PINTO; ANGELIS; HABE, 2004; PEREIRA; CARVALHO; CAMARGO, 2005), a aplicação de fungicidas visando ao controle dessa doença pode ser uma medida interessante por ser economicamente viável.

Argenta et al. (2001) constataram que o aumento do rendimento de grãos de milho é decorrente da distribuição mais uniforme das plantas, com redução do espaçamento entre linhas. Plantas espaçadas de modo equidistante competem minimamente por nutrientes, luz e outros fatores, favorecendo o melhor desenvolvimento das espigas. Estes autores verificaram que as maiores produtividades foram obtidas no espaçamento de $40 \mathrm{~cm}$ e não houve interação significativa nas densidades utilizadas (50 mil e 65 mil plantas.ha-1 ${ }^{-1}$.

$\mathrm{O}$ advento do milho geneticamente modificado, contendo o gene Bt (Bacillus thuringiensis), para o controle de lepidópteros-pragas na cultura do milho, tornou-se uma realidade no cenário agrícola do país (WAQUIL; VILLELA; FOSTER, 2002; MENDES; WAQUIL, 2009). Lavouras de milho com essa tecnologia estão sendo cultivados em grandes áreas, em diferentes populações de plantas e, até o presente momento, desconhece-se a influência destes fatores na severidade da mancha de cercospora.

O objetivo deste trabalho foi avaliar a severidade da mancha de cercospora em dois híbridos transgênicos de milho, cultivados na "safrinha" 2010, na área experimental do Campus de Chapadão do Sul, da Universidade Federal de Mato Grosso do Sul, em Chapadão do Sul, MS (Latitude: $18^{\circ} 48^{\prime} 00^{\prime \prime}$ S; Longitude: 52॰36’30” W; Altitude: $820 \mathrm{~m}$ ).

Foram utilizados os híbridos Agroceres Yieldgard AG 9010 YG (AG 9010 YG) e Advance NKAgrisure TL (Bt11). A semeadura foi feita no dia 15 de fevereiro e foram utilizadas duas densidades de cultivo de plantas, com diferentes espaçamentos entre linhas: a. $90 \mathrm{~cm}$ (convencional), contendo sete plantas.metro ${ }^{-1}$ (78 mil plantas ha $\left.{ }^{-1}\right) ;$ b. $45 \mathrm{~cm}$ (adensado), com quatro plantas.metro ${ }^{-1}$ (100 mil 
plantas ha-1). O delineamento experimental foi de blocos ao acaso, com seis repetições, em esquema fatorial (2x2), considerando-se como fatores: híbrido de milho e população de plantas. Cada parcela foi constituída por 10 metros de comprimento por cinco metros de largura, totalizando $50 \mathrm{~m}^{2}$. As plantas foram cultivadas sem o controle de pragas e conforme recomendações técnicas para a cultura do milho (FORNASIERI FILHO, 2007).

Foram realizadas duas avaliações da severidade da cercosporiose, a primeira no estádio seis (grãos leitosos) e a segunda no estádio sete (grãos pastosos). Avaliaram-se 20 plantas individualmente por parcela, escolhidas aleatoriamente, empregando-se a escala diagramática de Ward, Laing e Rijkenberg (1997a) com seis níveis de severidade (2, 5, 10, 20, 35 e $50 \%$ de área foliar afetada) como guia para auxiliar a estimar a porcentagem de área foliar doente das plantas.

A estimativa do rendimento de grãos das plantas foi realizada com as espigas colhidas das quatro linhas centrais das parcelas com espaçamento de 90 $\mathrm{cm}$ e de oito linhas, nas parcelas com espaçamento de $45 \mathrm{~cm}$.

Com a severidade das duas avaliações, calculouse a área abaixo da curva de progresso da doença (AACPD), conforme Campbell e Madden (1990). As médias de porcentagem de área foliar doente, AACPD e rendimento de grãos foram comparadas por meio do teste de Scott-Knott, a 5\% de probabilidade.

Houve ocorrência natural de doenças no ensaio, com predominância da cercosporiose e incidência muito baixa de mancha branca, causada por Pantoea ananatis (PACCOLA-MEIRELLES et al., 2001; BOMFETI et al, 2008).

Os resultados da influência da população de plantas na severidade da cercosporiose e no rendimento grãos dos genótipos encontram-se na Tabela 1. As avaliações de severidade da mancha de cercospora no estádio de grãos leitosos mostraram que os híbridos apresentaram maiores médias de severidade da doença no espaçamento convencional (78.000 plantas.ha-1), quando comparado ao adensado (100.000 plantas.ha-1). Já na segunda avaliação (grãos pastosos), os resultados indicaram interação significativa entre densidade de plantas e severidade da mancha de cercospora, havendo maior severidade da cercosporiose no espaçamento convencional em relação ao cultivo adensado apenas para o híbrido AG 9010 YG. Considerando a AACPD, que permite o acompanhamento do desenvolvimento da epidemia, observou-se ausência de interação significativa da população de plantas e a severidade da doença, sendo o resultado semelhante para ambos os híbridos.

Aventa-se a hipótese que, no espaçamento convencional, a propagação pelo vento do inóculo oriundo dos ciclos secundários da doença tenha sido facilitada pelo fluxo de ar ascendente com menos barreiras à sua passagem, isto é, devido ao maior espaçamento entre linhas, pode ter havido maior disseminação dos conídios pela passagem mais livre das correntes de vento, o que facilitou maior deposição destes nas folhas superiores. O contrário pode ter ocorrido no espaçamento adensado, em que as folhas sobrepostas umas às outras barraram o vento, interceptando os conídios e impedindo que fossem disseminados para as folhas superiores.

Casa et al. (2007) relataram que o aumento na densidade de plantas de milho proporcionou um acréscimo significativo da incidência das podridões do colmo, devido ao aumento competitivo intraespecífica por água, luz e nutrientes, levando ao maior estresse da planta e maior predisposição desta ao ataque de patógenos. Carvalho e Chalfoun (2001), no entanto, ao avaliarem o comportamento de doenças em dois genótipos de cafeeiros, em diferentes densidades populacionais, verificaram que os sistemas de plantios adensados e superadensados favoreceram a incidência da ferrugem do cafeeiro (Hemileia vastatrix), porém, reduziram a incidência da cercosporiose (Cercospora coffeicola). Os resultados obtidos neste trabalho diferem daqueles em que acusam que o aumento da densidade 
populacional favorece o incremento da severidade de doenças. Observa-se que o efeito de população de plantas sobre a intensidade de doenças tem se mostrado ser específico a cada patossistemas, levando-se em consideração os principais fatores que contribuem para o desenvolvimento de cada doença.

O rendimento de grãos dos híbridos, ao contrário da severidade da cercosporiose, foi significativamente maior com o aumento da densidade populacional. No espaçamento convencional, obteve-se uma produção média de $3.349,4 \mathrm{~kg} \mathrm{ha}^{-1} \mathrm{e}$, no adensado, uma produtividade média de $3.784 \mathrm{~kg} \mathrm{ha}^{-1}$ (aumento de 11,5\% no rendimento de grãos). Estes dados corroboram com Argenta et al. (2001), que comentaram que o aumento do rendimento de grãos de milho como consequência da redução do espaçamento entre linhas foi decorrente da distribuição mais uniforme das plantas, levando, provavelmente, à maior eficiência de interceptação da radiação solar pela área foliar fotossinteticamente ativa. Além disso, o maior rendimento de grãos apresentado nos espaçamentos adensados, no presente trabalho, pode ter sido também em decorrência da menor severidade da mancha de cercospora, quando comparado ao espaçamento convencional. Esta hipótese é baseada nas observações feitas por Brito et al. (2007) e Fantin et al. (2008), que relataram que a cercosporiose é uma doença que reduz a produtividade de grãos de milho, principalmente em semeadura tardia. Perdas relacionadas com a cercosporiose do milho, estimadas em 20 a 80\%, ocorrem quando tecidos fotossintetizantes perdem a função devido à queimadura das folhas pela doença, impedindo a translocação de fotossintetizados para os grãos, principalmente se a incidência da doença for maior nas folhas superiores (JULIATTI et al., 2007).

Os resultados obtidos neste trabalho permitem concluir que o incremento na população de plantas esteve relacionado com a redução da severidade da mancha de cercospora e contribuiu para o aumento do rendimento de grãos.

Tabela 1. Severidade da mancha de cercospora e produtividade de grãos de dois genótipos de milho, em função da densidade de plantas. CPCS/UFMS - Chapadão do Sul, MS.

\begin{tabular}{|c|c|c|c|c|c|c|c|c|}
\hline \multirow{5}{*}{ Genótipo } & \multicolumn{6}{|c|}{ Severidade da mancha de cercospora } & \multirow{3}{*}{\multicolumn{2}{|c|}{$\begin{array}{l}\text { Produtividade de grãos } \\
\qquad\left(\mathrm{kg} \cdot \mathrm{ha}^{-1}\right)\end{array}$}} \\
\hline & \multicolumn{4}{|c|}{ Porcentagem de área foliar afetada } & \multirow{2}{*}{\multicolumn{2}{|c|}{ AACPD }} & & \\
\hline & \multirow{2}{*}{\multicolumn{2}{|c|}{$\begin{array}{l}1^{\text {a }} \text {. avaliação } \\
\text { (grãos leitosos) } \\
\text { Densidade de } \\
\text { plantas (ha) }\end{array}$}} & \multirow{2}{*}{\multicolumn{2}{|c|}{$\begin{array}{l}2^{\mathrm{a}} \text {. avaliação } \\
\text { (grãos pastosos) } \\
\text { Densidade de } \\
\text { plantas (ha) }\end{array}$}} & & & & \\
\hline & & & & & \multicolumn{2}{|c|}{$\begin{array}{l}\text { Densidade de plantas } \\
\text { (ha) }\end{array}$} & \multicolumn{2}{|c|}{ Densidade de plantas (ha) } \\
\hline & 100.000 & 78.000 & 100.000 & 78.000 & 100.000 & 78.000 & 100.000 & 78.000 \\
\hline AG 9010 YG & $11,71 \mathrm{Aa}$ & $15,38 \mathrm{Ab}$ & $12,33 \mathrm{Aa}$ & $16,08 \mathrm{Ab}$ & $180,31 \mathrm{Aa}$ & $236,00 \mathrm{Ab}$ & $3555,10 \mathrm{Aa}$ & $3196,30 \mathrm{Ab}$ \\
\hline $\begin{array}{l}\text { Advance NK } \\
\text { Agrisure TL } \\
\text { (Bt11) }\end{array}$ & $10,68 \mathrm{Aa}$ & $13,89 \mathrm{Ab}$ & $12,75 \mathrm{Aa}$ & $14,63 \mathrm{Aa}$ & $175,75 \mathrm{Aa}$ & $213,87 \mathrm{Ab}$ & $4013,00 \mathrm{Aa}$ & $3502,50 \mathrm{Ab}$ \\
\hline C.V. $(\%)$ & & 16,98 & & 13,09 & & 12,23 & & 13,27 \\
\hline
\end{tabular}

Média de seis repetições; médias seguidas de letras distintas maiúsculas na coluna e minúsculas na linha, dentro de cada variável, diferem entre si pelo teste de Scott-Knott $(\mathrm{P}<0,05)$.

Fonte: Elaboração dos autores. 


\section{Referências}

ARGENTA, G.; SILVA, P. R. F.; BORTOLINI, C. G.; FORSTHOFER, E. L.; MANJABOSCO, E. A.; BEHEREGARAY NETO, V. Resposta de híbridos simples de milho à redução do espaçamento entre linhas. Pesquisa Agropecuária Brasileira, Brasília, v. 36, n. 1, p. 71-78, jan. 2001.

BOMFETI, C.A.; SOUZA-PACCOLA,E.A.; MASSOLA JÚNIOR, N. S.; MARRIEL, I. E.; MEIRELLES, W. F.; CASELA, C. R.; PACCOLA-MEIRELLES, L. D. Localization of Pantoea ananatis inside lesions of maize white spot disease using transmission electron microscopy and molecular techniques. Tropical Plant Pathology, Brasília, v. 33, n. 1, p. 63-66, 2008.

BRITO, A. H.; VON PINHO, R. G.; POZZA, E. A.; PEREIRA, J. L. A. R.; FARIA FILHO, E. M. Efeito da cercosporiose no rendimento de híbridos comerciais de milho. Fitopatologia Brasileira, Brasília, v. 32, n. 6, p. 472-479, 2007.

CAMPBELL, C. D.; MADDEN, L. V. Introduction to plant disease epidemiology. New York: John Willey, $1990.532 \mathrm{p}$.

CARVALHO, V. L.; CHALFOUN, S. M. Comportamento de doenças do cafeeiro em sistema de plantio adensado. In: SIMPÓSIO DE PESQUISA DOS CAFÉS DO BRASIL, 2., 2001, Brasília. Anais... Brasília, DF: EMBRAPA/MAA, 2001. v. 1, p. 77.

CASA, R. T.; MOREIRA, E. N.; BOGO, A.; SANGOI, L. Incidência de podridões do colmo, grãos ardidos e rendimento de grãos em híbridos de milho submetidos ao aumento na densidade de plantas. Summa Phytopathologica, Botucatu, v. 33, n. 4, p. 353-357, 2007.

CASELA, C. R.; FERREIRA, A. S. A cercosporiose na cultura do milho. Sete Lagoas, MG: Embrapa Milho e Sorgo, 2003. 65 p. (Circular técnica, 24).

CROUS, P. W.; GROENEWALD, J. Z.; GROENEWALD, M.; CALDWELL, P.; BRAUN, U.; HARRINGTON, T. C. Species of Cercospora associated with gray leaf spot of maize. Studies in Mycology, Utrecht, v. 55, p. 189-197, 2006.

FANTIN, G. M.; DUARTE, A. P.; DUDIENAS, C.; GALLO, P. B.; RAMOS JÚNIOR, E. U.; CRUZ, F. A.; RAMOS, V. J.; FREITAS, R. S.; DENUCCI, S.; TICELLI, M. Efeito da mancha de cercospora na produtividade do milho safrinha, no Estado de São Paulo. Revista Brasileira de Milho e Sorgo, Sete Lagoas, v. 7, n. 3, p. 231-250, 2008.
FORNASIERI FILHO, D. Manual da cultura do milho. Jaboticabal: FUNEP, 2007. 576 p.

JULIATTI, F. C.; BRANDÃO, A. M.; SANTOS, J. A.; LUZ, W. C. Fungicidas na parte aérea do milho: evolução de doenças fúngicas, perdas, resposta de híbridos e melhoria na qualidade da produção. Revisão Anual de Patologia de Plantas, Passo Fundo, v. 15, n. 1, p. $277-$ 334, 2007.

MENDES, S. M.; WAQUIL, J. M. Uso do milho Bt no manejo integrado de lepidópteros-praga: recomendações de uso. Sete Lagoas, MG: Embrapa Milho e Sorgo, 2009. (Comunicado técnico, 170).

PACCOLA-MEIRELLES, L. D.; FERREIRA, A. S.; MEIRELLES, W. F.; MARRIEL, I. E.; CASELA, C. R. Detection of a bacterium associated with a leaf spot disease of maize in Brazil. Journal of Phytopathology, Wissenschafts-Verlag, v. 149, n. 5, p. 275-279, 2001.

PEREIRA, O. A. P.; CARVALHO, R. V.; CAMARGO, L. E. A. Doenças do milho (Zea mays). In: KIMATI, H.; AMORIM, L.; REZENDE, J. A. M. et al. (Ed.). Manual de fitopatologia: doenças das plantas cultivadas. 4. ed. São Paulo: Agronômica Ceres, 2005. v. 2, p. 477-488.

PINTO, N. F. J.; ANGELIS, B. de; HABE, M. H. Avaliação da eficiência de fungicidas no controle da cercosporiose (Cercospora zeae-maydis) na cultura do milho. Revista Brasileira de Milho e Sorgo, Sete Lagoas, v. 3, n. 1, p. 139-145, 2004.

TRENTO, S. M.; IRGANG, H. H.; REIS, E. M. Efeito da rotação de culturas, da monocultura e da densidade de plantas na incidência de grãos ardidos em milho. Fitopatologia Brasileira, Brasília, v. 27, n. 6, p. 609-613, 2002.

WAQUIL, J. M.; VILLELA, F. M. V.; FOSTER, J. E. Resistência do milho (Zea mays L.) transgênico $(\mathrm{Bt})$ à lagarta-do-cartucho, Spodoptera frugiperda (Smith) (Lepidoptera: Noctuidae). Revista Brasileira de Milho e Sorgo, Sete Lagoas, v. 1, n. 3, p. 1-11, 2002.

WARD, J. M. J.; LAING, M. D.; RIJKENBERG, F. H. $\mathrm{J}$. Frequency and timing of fungicide applications for the control of gray leaf spot in maize. Plant Disease, St. Paul, v. 81, n. 1, p. 41-48, 1997a.

WARD, J. M. J.; LAING, M. D.; NOWELL, D. C. Chemical control of maize gray leaf spot. Crop Protection, Guildford, v. 16, n. 1, p. 265-271, $1997 \mathrm{~b}$. 
